\title{
Heterogeneity of Flow as an Explanation of the Multi- exponential Washout of Inert Gas from Skeletal Muscle ${ }^{1}$
}

\author{
Harvey V. Sparks and David E. Mohrman² \\ Department of Physiology, University of Michigan Medical School, \\ 7793 Medical Science II, Ann Arbor, Michigan 48104
}

Received June 2, 1976

\begin{abstract}
The explanation of the multi-cxponential washout of inert gas tracers from skeletal muscle is a source of controversy. The two most likely explanations are a heterogeneous flow pattern and countercurrent shunting of gas. Autoradiographs of canine skeletal muscle obtained after injection of ${ }^{85} \mathrm{Kr}$ indicate that heterogeneous flow is present in this preparation which would cause multi-exponential curves. This finding does not rule out an additional contribution of countercurrent shunting to the shape of the clearance curve.
\end{abstract}

\section{INTRODUCTION}

Clearance curves of ${ }^{133} \mathrm{Xe}$ or ${ }^{85} \mathrm{Kr}$ from skeletal muscle are multi-exponential (Kjellmer et al., 1967; Sejrsen and Tonneson, 1968). Kjellmer et al. (1967) proposed that the multi-exponential washout is due to clearance from various parallel compartments within muscle with differing flow-to-volume ratios. Sejrsen and Tonneson (1968) reached the conclusion that the multi-exponential nature of ${ }^{133} \mathrm{Xe}$ clearance from cat skeletal muscle is not likely to be caused by heterogeneous flow, but instead shunting of ${ }^{133} \mathrm{Xe}$ by diffusion between arteries and veins. We have obtained autoradiographs of canine skeletal muscle during clearance of ${ }^{85} \mathrm{Kr}$ which indicate that heterogenous flow may play the role suggested by Kjellmer et al.

\section{METHODS}

Male mongrel dogs weighing 20-30 kg were anesthetized with Innovar-Vet (McNeil) $(0.04 \mathrm{ml} / \mathrm{kg})$ followed by sodium pentobarbital $(20 \mathrm{mg} / \mathrm{kg})$. Additional pentobarbital was administered as necessary to maintain adequate anesthesia.

We used a calf muscle preparation which we have described in detail in an earlier publication (Mohrman et al., 1973). The calf was skinned, the paw was removed, and all structures in the popliteal region except the femoral artery and vein and the femur were transected. The femoral artery was cannulated just proximal to the popliteal region and perfused by a finger pump drawing blood from the contralateral femoral artery. The femoral vein was also cannulated in the popliteal region and the blood draining the calf was returned to the animal via the contralateral femoral vein. Sodium heparin ( $600 \mathrm{units} / \mathrm{kg}+200 \mathrm{units} / \mathrm{kg} / \mathrm{hr}$ ) was used to prevent blood clotting in the extra

${ }^{1}$ Research supported by United States Public Health Service Grant HL-14516.

${ }^{2}$ Present address: Department of Physiology, University of Minnesota, Duluth, Minnesota 55812. 
corporeal circulation and microembolization. Constant flow was set at a level $[22.3 \pm$ $3.5(\mathrm{SEM}) \mathrm{ml}(100 \mathrm{~g} \cdot \mathrm{min})^{-1}$ ] which gave a perfusion pressure similar to the systemic arterial pressure of the $\operatorname{dog}(\simeq 100 \mathrm{~mm} \mathrm{Hg})$.

${ }^{85} \mathrm{Kr}$ (approximately $0.1 \mathrm{mC}$ ) dissolved in $0.5 \mathrm{ml}$ of $0.9 \%$ saline was injected into the arterial perfusion line. The disappearance of ${ }^{85} \mathrm{Kr}$ from the calf was monitored with a 2 -in diameter sodium iodide crystal mounted in a collimated probe. Counting intervals of the digital rate meter ranged from 3 to $30 \mathrm{sec}$ depending upon the rate of clearance of ${ }^{85} \mathrm{Kr}$ and amount of radioactivity in the tissue. A total of seven complete ${ }^{85} \mathrm{Kr}$ clearance curves were obtained from four dogs. The multi-exponential clearance curves were resolved into three mono-exponential components by a computer program which optimizes parameters according to a weighted least squares error criterion (Chandler, 1971).

Tissue autoradiographs were made to determine the anatomical representation of the resolved components of the ${ }^{85} \mathrm{Kr}$ clearance curves. For this, the circulation of the calf was arrested at a selected time after the injection of another ${ }^{85} \mathrm{Kr}$ bolus by clamping the inflow and outflow tubing. The calf muscle was immediately removed and frozen in acetone at $-79^{\circ}$. Transverse frozen sections of the calf were prepared and placed on $\mathrm{X}$-ray film for times dependent on radioactivity contained within the slices (Thorburn et al., 1963).

On the basis of autoradiograph evidence (see Results) only the fastest two of the three resolved components of the ${ }^{85} \mathrm{Kr}$ clearance curves were judged to represent muscle flow. The third component appears to represent clearance from bone marrow and connective tissue. The zero time intercept and the rate constant, for each of the two fastest mono-exponential components ( 1 and 2 ) of the clearance curves was calculated by standard methods (Kety, 1951).

\section{RESULTS}

Figure 1 shows the first 30 min of a typical clearance curve of ${ }^{85} \mathrm{Kr}$ from dog calf. The bolus of saline containing the ${ }^{85} \mathrm{Kr}$ was injected intra-arterially at time zero. The clearance curve itself (dotted line) is multi-exponential as indicated by the curvature on the semilogarithmic plot. The solid lines indicate the three mono-exponential components selected by a weighted least squares error criterion which sum algebraically to give the raw data. The determination of the slope of component 3 was on the basis of the last $30 \mathrm{~min}$ of washout data, not shown in Fig. 1.

The zero time intercepts of components 1 and 2 for the seven curves averaged $48.9 \pm$ 14 (SEM) and $51.1 \pm 14.1 \%$ of the total radioactivity in the two components, respectively. The rate constants were $0.85 \pm 0.17$ and $0.16 \pm 0.01 \mathrm{~min}^{-1}$ for components 1 and 2 , respectively.

Figure 2 shows autoradiographs from cross sections of three calves removed and frozen $15 \mathrm{sec}, 4 \mathrm{~min}$, and $20 \mathrm{~min}$ following injection of a bolus of ${ }^{85} \mathrm{Kr}$. Inspection of the resolved components of the clearance curve in Fig. 1 indicates that radioactivity remaining in the calf at $20 \mathrm{~min}$ is responsible for component 3 . The 20 -min autoradiograph in Fig. 2 shows that nearly all of the radioactivity is located in the marrow of the tibia with additional small deposits in soft tissue. Components 1 and 2 occur at earlier times indicating that they reflect washout from soft tissue, predominantly the muscle of the 


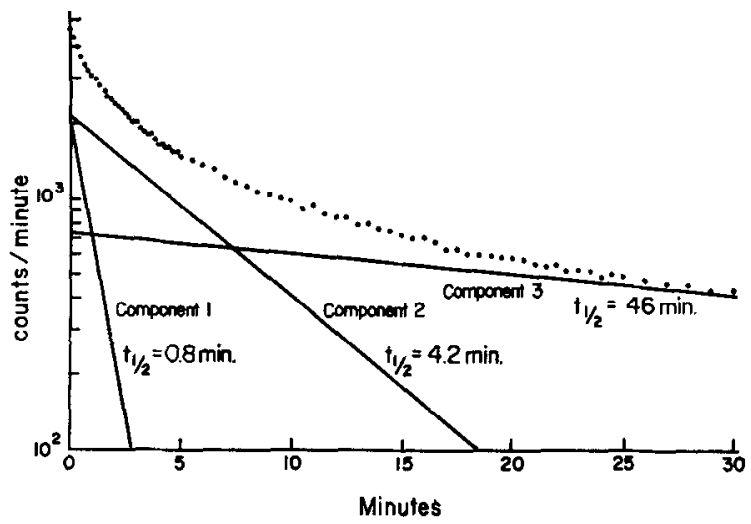

Fig. 1. Semilogarithmic plot of the first $30 \mathrm{~min}$ of a $60-\mathrm{min}{ }^{85} \mathrm{Kr}$ disappearance curve (background subtracted) from dog calf muscle and bone after intra-arterial injection at zero time. The curve was resolved into three mono-exponential components as described in Methods.

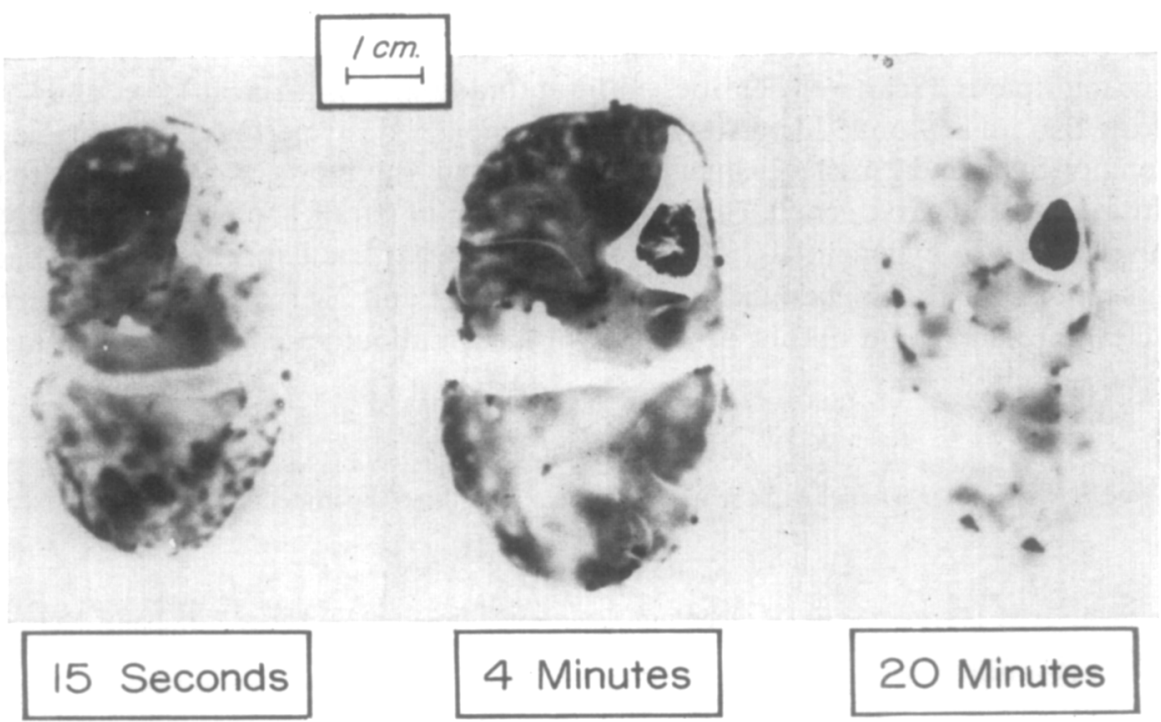

FIG. 2. Autoradiographs made from cross sections of dog calf muscles rapidly frozen $15 \mathrm{sec}, 4 \mathrm{~min}$, and $20 \mathrm{~min}$ after intra-arterial bolus injection of ${ }^{85} \mathrm{Kr}$. Autoradiograph film exposure times were 22, 72 , and $336 \mathrm{hr}$ respectively.

calf. Note the variation in the density of the 15-sec and 4-min autoradiographs, indicating various rates of washout of ${ }^{85} \mathrm{Kr}$.

\section{DISCUSSION}

Several investigators have proposed that the multi-exponential nature of inert gas clearance from muscle is caused by removal of the gas from multiple parallel compartments with varying flow to volume ratios (Kjellmer et al., 1967; Paradise et al., 1971; Thompson et al., 1959). Sejrsen and Tonneson (1968) argue against this possibility on the basis of their observation that small local deposits of ${ }^{133} \mathrm{Xe}$ cleared multi-exponentially. They suggested that the small local deposits should clear mono-exponenti- 
ally. They predicted that in such a small area, diffusion of gas would prevent the development of large concentration gradients which would occur if different flow to volume ratios were to exist so close to each other. Although their local deposits were only $0.5 \mathrm{~mm}$ deep, they were approximately $10 \mathrm{~mm}$ in diameter. This is a large enough area to encompass several different densities on the autoradiograph in Fig. 2. Thus, it appears that concentration gradients may exist within the local deposits observed in Sejrsen and Tonneson's experiments (1968). If this is the case, multi-exponential clearance of inert gas for the local deposits could be caused by heterogeneity of flow. This finding does not rule out a causal role for counter current exchange in the shape of inert gas clearance curves of muscle. We would only suggest that a significant fraction of the shape is due to heterogeneity of flow.

We do not have reason to believe that the variability of the density of the autoradiographs in Fig. 2 is an artifact. Mistakes in preparation of the tissue, for example, slow freezing following blood vessel clamping, allowing the tissue to thaw at a later time, or poor polishing of the surface of the tissue slice, would allow ${ }^{85} \mathrm{Kr}$ to become more equally distributed throughout the slice and/or reduce the resolution of the autoradiograph which would obscure any concentration differences.

The multiple and scattered densities of the autoradiographs taken at $15 \mathrm{sec}$ and $4 \mathrm{~min}$ indicate that no anatomic correlates (parallel homogeneously perfused compartments) of components 1 and 2 exist. Kjellmer et al. (1967) and Van Liew (1967) point out that a multi-exponential curve generated by a large number of parallel compartments may be resolved into two exponentials. This is apparently what has happened in the experiments reported here. The parameters of components 1 and 2 serve only to characterize the clearance curve and do not provide information about specific compartments of skeletal muscle.

\section{ACKNOWLEDGEMENT}

We wish to thank Dr. Daniel A. Schnarr for his help with these experiments.

\section{REFERENCES}

Chandler, J. P. (1971). "STEPIT Quantum Chemistry Program Exchange." Indiana University Chemistry Department, Program 66.

KeTY, S. (1951). The theory and applications of the exchange of inert gas at the lung and tissues. Pharmacolog. Rev. 3, 1-41.

Kjellmer, I., Lindoifre, I., Prfrovsky, I., and Tonnesen, H. (1967). The relation between blood flow in an isolated muscle measured with the ${ }^{133} \mathrm{Xe}$ clearance and a direct recording technique. Acta Physiol. Scand. 69, 69-78.

Mohrman, D. E., CANT, J. R., AND SParks, H. V. (1973). Time course of vascular resistance and venous oxygen changes following brief tetanus of dog skeletal muscle. Circ. Res. 33, 323-336.

Paradise, N. F., Swayze, C. R., Shin, D. H., And Fox, I. J. (1971). Perfusion heterogeneity in skeletal muscle using tritiated water. Amer. J. Physiol. 220, 1107-1115.

SeJRSEN, P., AND ToNNESEN, K. H. (1968). Inert gas diffusion method for measurement of blood flow using saturation techniques. Circ. Res. 22, 679-693.

Thompson, A. M., Cavert, H. M., Lifson, N., And Evans, R. L. (1959). Regional tissue uptake of $\mathrm{D}_{2} \mathrm{O}$ in perfused organs: ral liver, dog heart and gastrocnemius. Amer. J. Physiol. 197, 897-902.

Thorburn, G. D., Kopold, H. H., Herd, J. A., Hollenberg, M., O’Morchoe, C. C. C., and Barger, A. C. (1963). Intrarenal distribution of nutrient blood flow determined with ${ }^{85} \mathrm{Kr}$ in the unanesthetized dog. Circ. Res. 13, 290-307.

VAN LIEW, H. D. (1967). Graphic analysis of aggregates of linear and exponential processes. $J$. Theor. Biol. 16, 43-53. 